Received: 2016.09 .12

Accepted: 2016.12 .31

Published: 2017.09.15

Authors' Contribution:
A Study Design
B Data Collection
C Statistical Analysis
D Data Interpretation
E Manuscript Preparation
F Literature Search
G Funds Collection

\section{Multi Detector Computed Tomography Fistulography In Patients of Fistula-in-Ano: An Imaging Collage}

\author{
Shuchi Bhatt ${ }^{1 \mathrm{ABG} D E \mathrm{~B}}$, Bhupendra Kumar Jain ${ }^{2 \mathrm{CW}}$, Vikas Kumar Singh ${ }^{1 \mathrm{BGD}}$ \\ ${ }^{1}$ Department of Radio-Diagnosis, University College of Medical Sciences (University of Delhi) and Guru Teg Bahadur Hospital, \\ New Delhi, India \\ 2 Department of Surgery, University College of Medical Sciences (University of Delhi) and Guru Teg Bahadur Hospital, \\ New Delhi, India
}

Author's address: Shuchi Bhatt, Department of Radio-Diagnosis, University College of Medical Sciences (University of Delhi) and Guru Teg Bahadur Hospital, New Delhi, India, e-mail: drshuchi@hotmail.com
MeSH Keywords:

PDF file:

\section{Summary}

Fistula-in-ano, or perianal fistula, is a challenging clinical condition for both diagnosis and treatment. Imaging modalities such as fistulography, anal endosonography, perineal sonography, magnetic resonance imaging (MRI), and computed tomography (CT) are available for its evaluation. MRI is considered as the modality of choice for an accurate delineation of the tract in relation to the sphincter complex and for the detection of associated complications. However, its availability and affordability is always an issue. Moreover, the requirement to obtain multiple sequences to depict the fistula in detail is cumbersome and confusing for the clinicians to interpret. The inability to show the fistula in relation to normal anatomical structures in a single image is also a limitation.

Multi detector computed tomography fistulography (MDCTF) is an underutilized technique for defining perianal fistulas. Acquisition of iso-volumetric data sets with instillation of contrast into the fistula delineates the tract and its components. Post-processing with thin sections allows for a generation of good quality images for presentation in various planes (multi-planar reconstructions) and formats (volume rendered technique, maximum intensity projection). MDCTF demonstrates the type of fistula, its extent, whether it is simple or complex, and shows the site of internal opening and associated complications; all in easy to understand images that can be used by the surgeons. Its capability to represent the entire pathology in relation to normal anatomical structures in few images is a definite advantage. MDCTF can be utilized when MRI is contraindicated or not feasible.

This pictorial review shares our initial experience with MDCT fistulography in evaluating fistulain-ano, demonstrates various components of fistulas, and discusses the types of fistulas according to the standard Parks classification.

Anal Canal • Diagnostic Imaging • Magnetic Resonance Imaging • Multidetector Computed Tomography • Rectal Fistula

http://www.polradiol.com/abstract/index/idArt/901523

\section{Background}

Fistula-in-ano is a common clinical condition with a prevalence of approximately 1 per 10,000. It affects predominantly young adult males in their fourth decade of life. [1] Males are affected twice as commonly as females [1]. Fistula-in-ano is an abnormal tract that connects an external skin opening in the perianal region to the enteric lumen through an internal opening, most often in the anal canal.
Chronic infection of the anal glands commonly presents as perianal pus discharge and discomfort [2]. Treatment is aimed at eradication of the fistulous tract, mainly by surgical intervention with preservation of anal continence. Occult disease is not detected clinically and therefore remains untreated, commonly resulting in recurrence and multiple failed surgeries $[3,4]$. The greatest clinical challenge is to accurately map the entire length of the primary tract in relation to the external sphincter. Moreover, 
delineation of all the secondary extensions of the tract and of the internal opening is essential to provide a complete preoperative assessment of the disease process; based on this, a meticulous and adequate surgical planning can be performed. Imaging allows the operating surgeon to undertake a dissection which causes the least possible damage to the external sphincter muscle, as it is responsible for $80 \%$ of the continence. Clinicians usually rely on examination under anesthesia (EUA) for this purpose, but loss of muscle tone makes it difficult to identify the primary tract in relation to the external sphincter, pubo-rectalis, and levator ani muscles. The internal opening is frequently not detected, and extensions of the tract are also missed in as many as $25 \%$ of patients [5]. Imaging techniques that allow for a direct visualization of the anorectal region, sphincters, pelvic floor muscles, the surrounding fat-filled peri-anal and peri-rectal spaces, and the fistulous tract are essential for demonstration of all components of the fistula. Excellent soft tissue contrast resolution and multiplanar capability of MRI can produce images in the required sagittal and coronal planes, which is useful in defining the disease and its extent in relation to normal structures. Imaging findings on MR are mostly concordant with the surgical findings [6,7]. Multiple sequences are needed for delineation of the complete pathology on MR, and sometimes, even special endoluminal coil is required, thus increasing the complexity of the modality. Also, MRI cannot be used in certain situations where a relative or an absolute (due to presence of ferromagnetic implants) contraindications are present. Besides, imaging may be suboptimal if no intravenous contrast is used due to renal insufficiency. Moreover, availability and affordability are always an issue with MRI, especially in the developing world. Contrast fistulography, an investigation of yester years, provides little information which is not usually adequate for treatment planning. Some authors believe that it is an "unreliable and inaccurate" modality [8].

On CT, the attenuation of anal sphincter and pelvic floor is similar to the fistula itself and therefore CT has not been employed for evaluating fistula-in-ano [9]. It is believed that the role of CT is limited to the diagnosis of fistula-associated pelvic abscesses, when other imaging is not feasible [9]. However, contrast instillation into the external opening allows for a visualization of the fistulous tract which, if combined with the MDCT, results in a technique called MDCT fistulography (MDCTF). The acquisition of iso-volumetric data sets allows for reformation of images in any plane for depicting the abnormal anatomy of the anorectal region [9]. In clinical practice, this novel technique has been sparingly used for evaluation of the fistula-in-ano [10-12]; however, this modality is expected to have a better diagnostic performance than CT due to an enhanced spatial resolution.

The purpose of this article is to present findings of 64-slice MDCT fistulography in patients with fistula-in-ano. The pictorial review depicts the various components of the disease process, along with the different types of fistulas.

\section{Clinical Anatomy of Anorectal Region}

Surgeons describe the "anal clock" as the anus being viewed in the lithotomy position that is used for fistula surgery. 12 o'clock is the anterior perineum, and 6 o'clock is the natal cleft; 3 o'clock refers to the left lateral aspect, and 9 o'clock to the right of the anal site. Both the internal (mucosal in bowel) and external (cutaneous) opening of the fistulous tract is referred in relation to the anal clock. The Goodsall [13] rule governs the location of the internal opening with respect to the perianal external opening. The internal sphincter is an involuntary smooth, circular muscle of the rectal wall and is responsible for $85 \%$ of the resting anal tone. On the other hand, the external sphincter is composed of striated muscles, and its strong voluntary action is responsible for anal continence. A potential intersphincteric space, filled with fat, is present between the two sphincters. The external sphincter is continuous superiorly with the pubo-rectalis part of the levator ani muscle, which forms the anorectal sling. The importance of this sling has been known for decades; it is crucial to determine if the fistula enters the anal canal above or below it, as its surgical division leads to incontinence [14].

\section{Pathology of Fistula-in-Ano}

Idiopathic perianal fistulas represent the most common variety, other causes include Crohn's disease, tuberculosis, trauma, pelvic infection, pelvic malignancy, and radiation therapy. Anal glands located in the intramuscular or intersphincteric plane, at the level of the dentate line in the anal canal, become infected, suggesting a crypto-glandular etiology [15]. A persistent infection of the anal glands may track circumferentially or spread in an axial direction, resulting in different types of fistulas. When the infection travels into the inter-sphincteric plane and reaches the skin, an inter-sphincteric fistula results. The infection may pass through both the internal and external anal sphincters to enter the bowel lumen and the ischio-anal fossa, respectively, resulting in a trans-sphincteric tract. Abscesses may form along the fistulous tracts, and abscesses associated with inter-sphincteric fistulas are perianal or inter-sphincteric in location, while ischio-rectal fossa abscesses are associated with trans-sphincteric fistulas. Rarely, the infection tracks upward, over the sphincter complex, resulting in a supra-sphincteric fistula. Sepsis, arising within the pelvis and communicating with the rectum, may track down to the skin, via a tract traversing through the ischiorectal fossa, forming extra-sphincteric or a trans-levator fistulous tracts.

\section{Parks Classification}

This surgical classification is the most comprehensive and practical classification that is currently used; it classifies all fistulas into one of the five following types - superficial, inter-sphincteric, trans-sphincteric, supra-sphincteric, and extra-sphincteric [16]. The classification of Parks gives an idea regarding the extent of the required surgical intervention, based on the involvement of the external sphincter and the location of the internal opening. An inter-sphincteric fistula is the commonest type (60-70\%), followed by the trans-sphincteric type, (20-30\%) [17]. Supra-sphincteric 


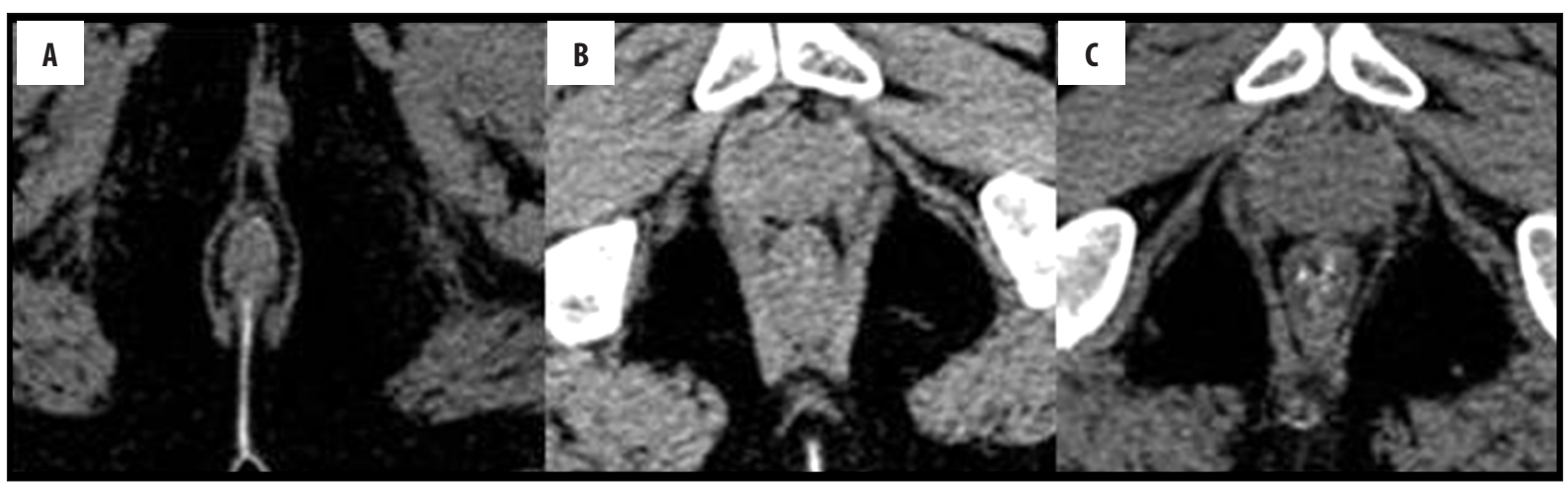

Figure 1. Normal anatomy of the anal region at three different levels on MDCT. (A) Axial scan - below the pubo-rectalis, (B) at the level of the pubo-rectalis, (C) supralevator level above the pubo-rectalis.

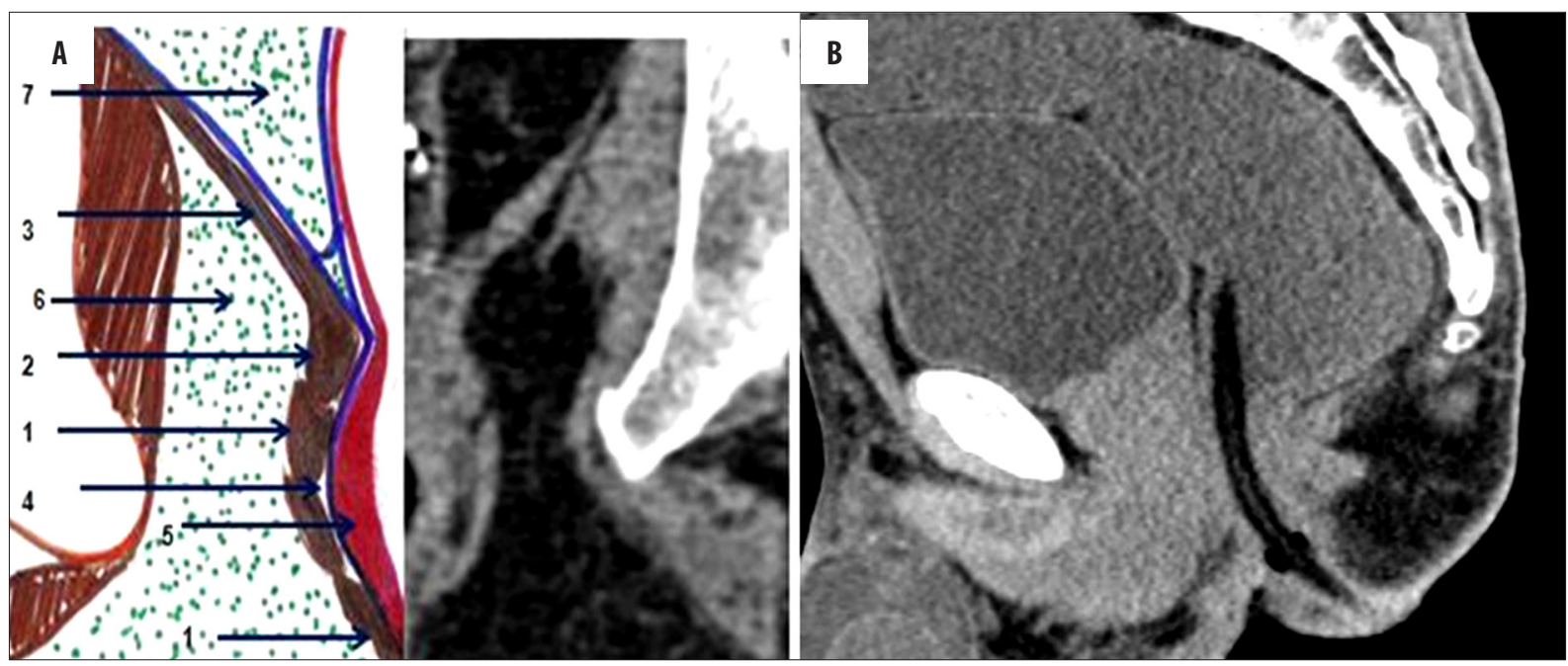

Figure 2. (A) Composite coronal image showing the anorectal region. Diagrammatic representation of the anorectal canal (in a cut section) with the sphincter complex and surrounding structures (left side). A corresponding MDCT image is presented on the right. Images also show isodense external sphincter (1) continuous upwards with the pubo-rectalis (2). Pubo-rectalis (2) is the infero-medial thickened part of the levator ani muscle (3) at the anorectal junction. Hypodense inter-sphincteric fat plane (4) is seen in between the external and internal sphincters. Internal sphincter (5) forming the anal wall cannot be discerned due to opposition of the wall of the anal canal. The infra- (6) and the supra-levator (7) fat is also very well appreciated below and above the levator ani, respectively. (B) Mid-sagittal scan showing the normal anorectal angle formed at the anorectal junction by the pubo-rectalis (arrow) part of the levator ani. A thin sleeve of fat is appreciated between the posterior rectal wall and the levator muscle. A tube has been placed in the anal canal for clear demonstration.

fistulas are uncommon, and the extra-sphincteric type usually develops due to an inflammatory involvement of the rectal wall resulting from another cause. The imaging counterpart of the classification of Parks is the St. James's University Hospital grading scheme [18,19], based on the MRI appearance of perianal fistulas in the axial and coronal planes. This classification also distinguishes secondary extensions and abscesses; it classifies fistulas into 6 grades. Grade 0 is a normal-appearing anal canal. An inter-sphincteric fistula, if simple, is Grade 1, and Grade 2, if a secondary tract or abscess is present. Grade 3 fistula is a simple trans-sphincteric fistula, and with a secondary tract or abscess it becomes a Grade 4 fistula. Grade 5 fistula represents a complicated abscess with a supra- or trans-levator component.

\section{Imaging}

Various imaging modalities have been used for preoperative assessment of fistula-in-ano. Conventional fistulography was used before the advent of cross-sectional imaging. The sensitivity of fistulography in identifying the primary fistulous tract is $89 \%$ [20]; it is lower (56\%) for detecting secondary extensions. [4] The level of internal opening is difficult to recognize, and the entire tract length is not seen, if blocked by debris.

Anal endosonography is the only technique which can depict the anal sphincter complex in detail [3]. However, being an operator dependent modality, its results have been reported to be either inferior or superior, in comparison to MR examinations, for the evaluation of fistulain-ano [21-23]. Structural anatomy beyond the external sphincter cannot be demonstrated, and therefore deeper extensions of the primary tract into the ischioanal/ischiorectal and supralevator spaces are missed. As regards surgically important parameters of perianal fistulas, including the primary tract, internal opening, secondary tract, abscesses, and horseshoeing, MRI showed a sensitivity of $87.5-95 \%$ and specificity of $80-95 \%$, and is considered to be 


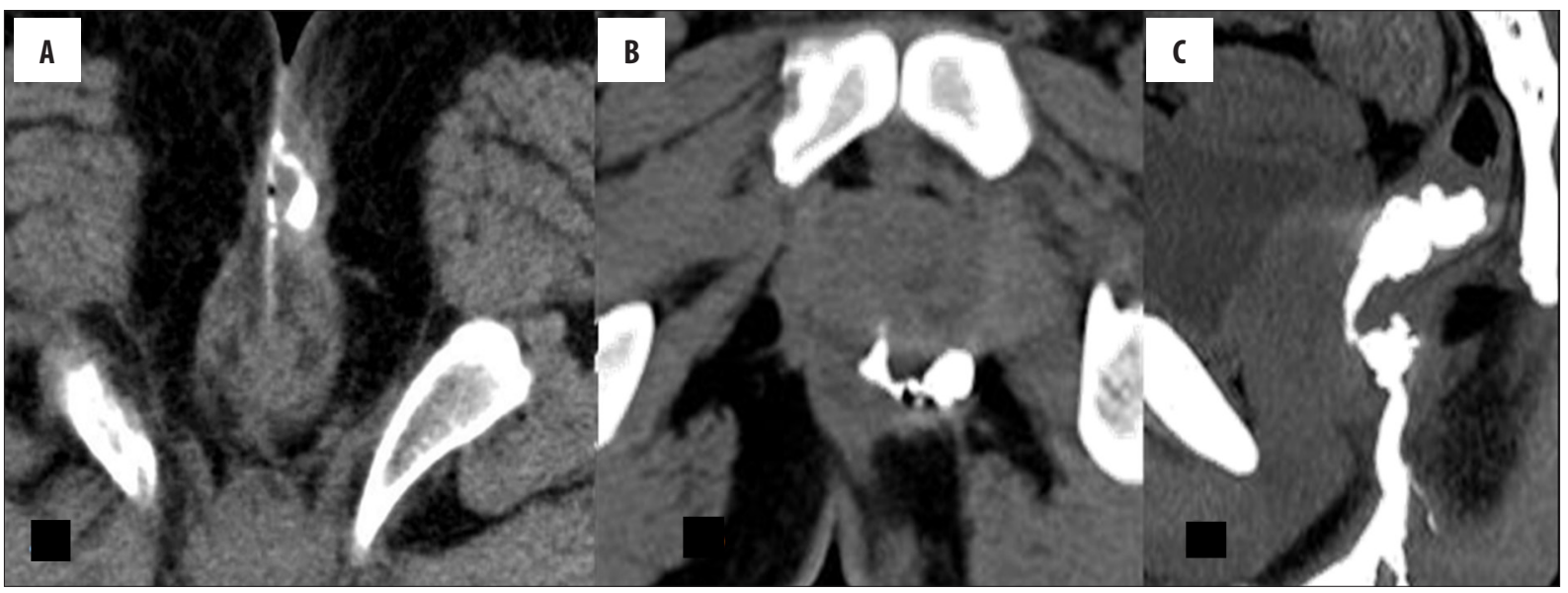

Figure 3. (A) External opening. Axial scan showing an external opening at midline $60^{\prime}$ clock position leading to a curved tract seen in relation to the anal canal. Soft tissue around the tract suggests inflammatory tissue. (B, C) Internal opening. (B) Axial image showing internal opening at 6 o'clock position. An inter-sphincteric component of the tract is also seen. (C) Sagittal scan showing the entire supra-sphincteric tract with an infra-sphincteric collection and internal opening with consequent spill in the rectum.

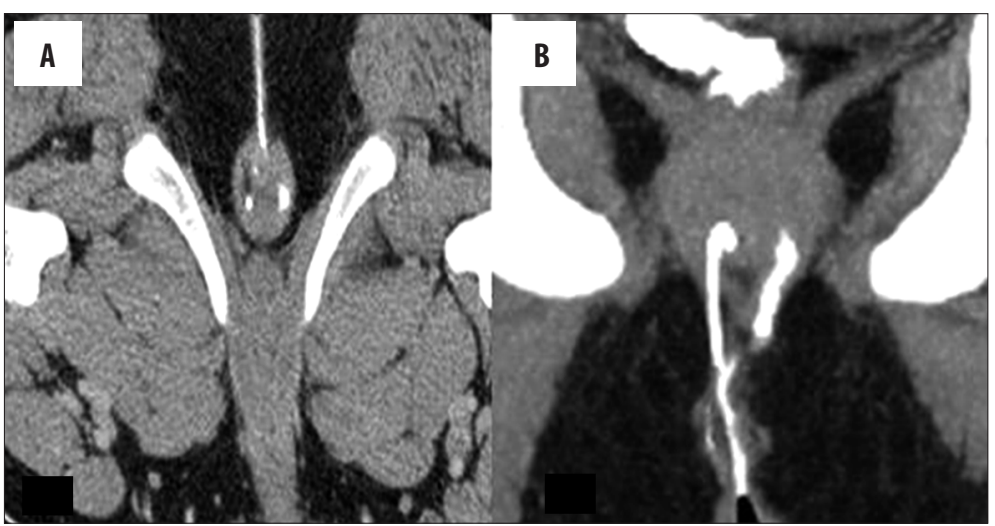

Figure 4. Primary tract (simple). (A) Axial image - a left, thicker tract is seen to cut the external sphincter, while the contralateral thinner tract is seen in the inter-sphincteric plane. (B) Coronal MPR image - inter-sphincteric tract is seen on the right side and the trans-sphincteric on the left side of the image in relation to the sphincter complex.

the gold standard investigation [24]. Primary tract delineation is better achieved with the use of endoluminal coils, whereas extensions are better imaged with the use of superior field of view of the external coil [25]. Therefore, a combination of the two coils would provide an optimal examination. However, patient tolerance to endoluminal coils is low, and a proper image view for adequate surgical dissection may not be available [26].

Dynamic contrast-enhanced MRI has a reported sensitivity of $97 \%$ and specificity of $100 \%$ for detection of fistulas, and is considered to be the best technique for its delineation [27]. Noninvasiveness and high diagnostic accuracy [28] in mapping the perianal fistulas are the definite advantages of MRI.

\section{MDCT Fistulography}

This is a novel technique for evaluation of perianal fistulas. It is based on acquisition of thin sections with MDCT (16 or more slice MDCT), with simultaneous instillation of watersoluble, iodinated contrasts into the active external perianal opening. The findings of MDCTF confirmed by MRI and/or surgery are presented.

\section{Technique of MDCT Fistulography}

The patient was asked to lie prone on the gantry table. Cannulation of the external perianal opening was performed with an intravenous catheter, and 5\% iodinated contrast was instilled. Axial scanning was preformed, from the mid-sacrum to the gluteal fold, with $140 \mathrm{KV}, 205 \mathrm{mAs}$ and $64 \times 1 \mathrm{~mm}$ collimation, to obtain $2 \mathrm{~mm}$-thick slices. Images were studied in axial, coronal and sagittal planes by a radiologist blinded to clinical details. Pathological findings that were assessed on MDCT fistulography included the location, course and extent of the primary tract, whether the tract was simple or complex, and the position of the internal opening. Presence of secondary tracts and abscesses was also noticed. The bone and soft tissues were seen for the presence of any abnormality. The fistula was classified according to the Parks classification.

\section{Normal MDCT Findings of Anorectal Region}

A normal anorectal region. Soft tissues, i.e., rectal/anal wall, external sphincter, and the pelvic floor muscles have a similar soft tissue density and cannot be differentiated by attenuation values but can be recognized by their location. High resolution images of MDCT allow for a visualization of the inter-sphincteric fat plane as a curvilinear negative density separating the anal wall (internal sphincter) and 


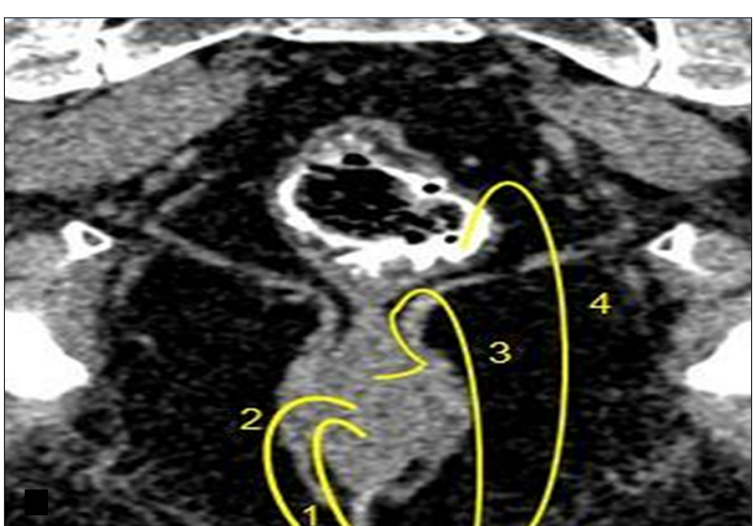

Figure 5. Shows the different types of fistulas represented diagrammatically on the MDCTF image in coronal view (1 - Inter-sphincteric, 2 - Trans-sphincteric, 3 - Suprasphincteric and 4 - Extra-sphincteric), according to Parks classification.

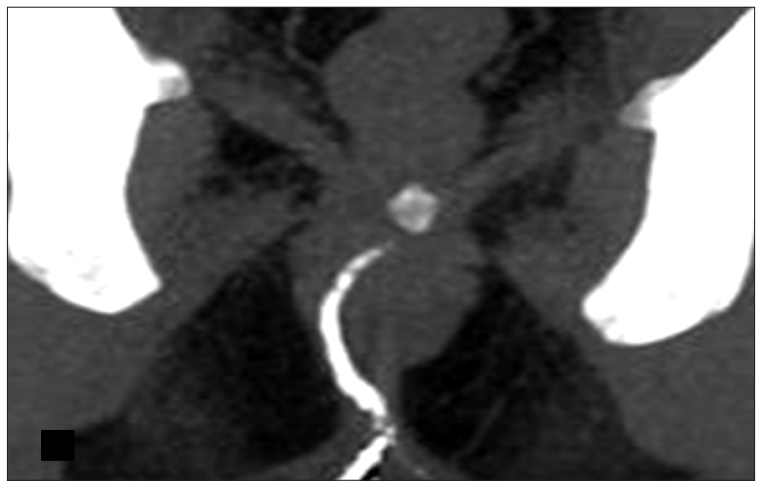

Figure 6. Simple inter-sphincteric fistula-in-ano. A curvilinear tract extending from the midline along the inter-sphincteric plane to open high up in the anal canal in the midline.

the external sphincter (Figure 1A-C). It is better perceived in the posterior and lateral location. The external sphincter is continuous superiorly with the pubo-rectalis muscle, which is the thickened and most infero-medial part of the levator ani. The levator ani muscle is best visible on the coronal view, forming a sling extending infero-medially from the lateral pelvic wall to the anorectal wall, forming a waist at the level of the anorectal junction (Figure 2A). A sagittal image (Figure 2B) of the anorectal junction shows a change in curvature of the anal canal, corresponding to the pubo-rectalis muscle which appears as a sling around the anal canal on the axial view, with both limbs coursing anteriorly, attaching to the pubic bone. Any pathology medial to the pubo-rectalis muscle is present in the supralevator space, whereas the infralevator disease is seen lateral to the muscle in axial sections. Extension of the disease across the levator is best seen in the coronal view. The anal lumen, with or without air density or contrast, is collapsed and therefore the anal canal appears rounded in shape until the anorectal junction, where it assumes an oblong shape in the axial view. The ischio-anal and ischio-rectal fossa are fat-containing fossae abutting the anal canal on either side in the infra-levator part, and are seen as neat negative density triangular fossae. Abnormal tracts and inflammation are easily recognized in their background. Sometimes, on the sagittal view, a linear soft

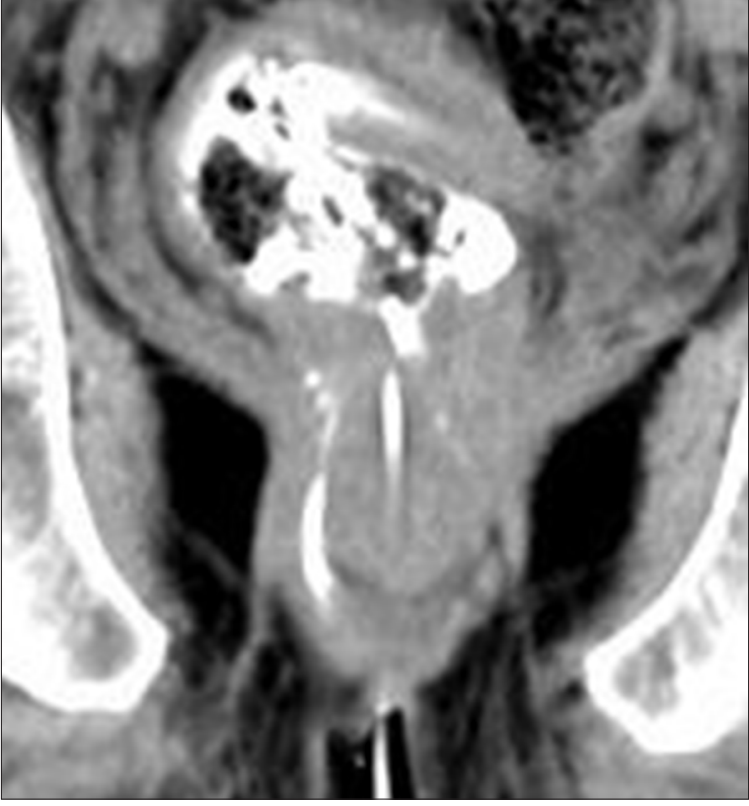

Figure 7. Inter-sphincteric tract with a supralevator extension suggesting a complex fistula and spill into the rectum. The internal opening is not evident in this coronal image.

tissue density is seen to extend from the coccygeal tip to just below the level of the pubo-rectalis or the anorectal junction, which corresponds to the deep part of the external sphincter. The different parts of the external sphincter are usually not recognized separately.

\section{Components of Fistula-in-Ano}

The external opening, present in the peri-anal location, described as o'clock position, leads into a fistulous tract, with or without a demonstrable internal opening in the anal/rectal mucosa. (Figure 3A-C). Most commonly, the internal opening is present at the level of the dentate line in the anal canal but occasionally may lie above it in the anal canal or the rectum. Spill of contrast into the bowel lumen confirms a patent internal opening on MDCTF and is recognized as a contrast-filled, innermost part of the tract in the anal/rectal wall (Figure 3B, 3C). The primary tract is the main tract connecting the external and internal openings (Figure 4). Depending on the location and course of the primary tract, perianal fistulas have been classified into four types [16] (Figure 5). In the inter-sphincteric type, infection develops in the inter-sphincteric plane, between the internal and external sphincters, traverses down and ruptures onto the skin without traversing the external fistula (Figures 6, 7). When the inter-sphincteric infection penetrates the external sphincter to reach the ischioanal fossa, a trans-sphincteric tract is formed (Figures 8-10). Inter-sphincteric fistulas are most common $(70-80 \%$ of cases), while the trans-sphincteric type is seen in $20 \%$ of patients [17]. Supra-sphincteric (Figure 11) and extrasphincteric fistulas are uncommon and develop when the inter-sphincteric tract extends superiorly to reach above the levator plate, and then traverses inferiorly through the ischioanal fossa (supra-sphincteric) or, in the case of primary pelvic disease such as Crohn's disease or diverticulitis, the inter-sphincteric tract extends down through the 


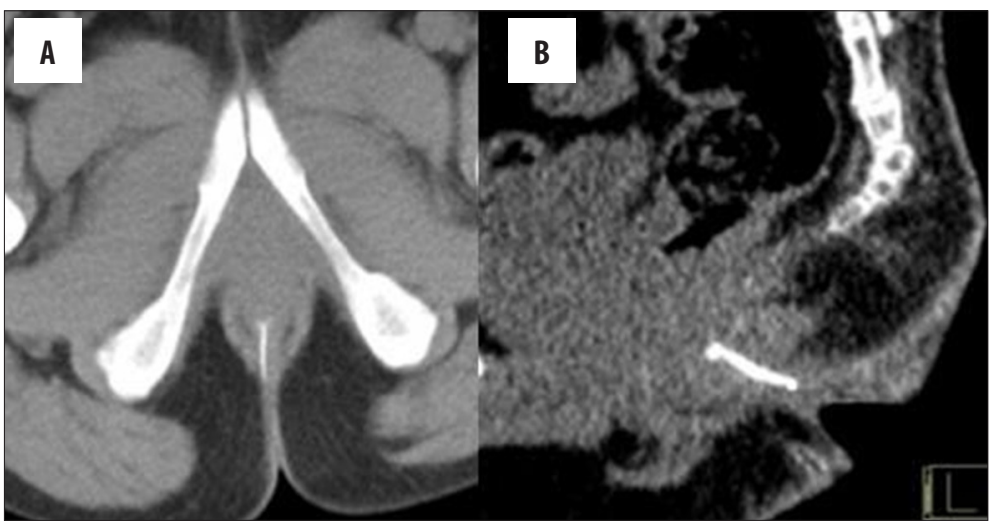

Figure 8. Low trans-sphincteric fistula. (A) Axial. (B) Sagittal view.

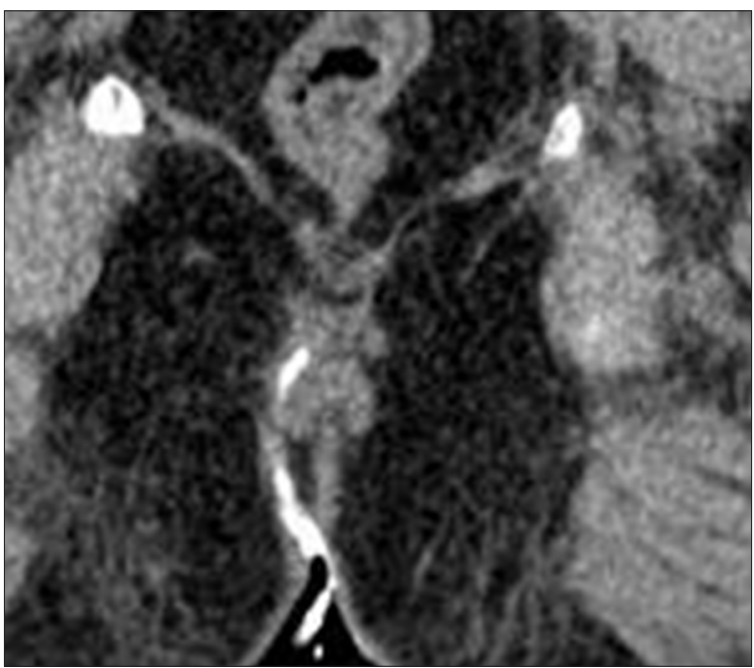

Figure 9. High trans-sphincteric fistula.

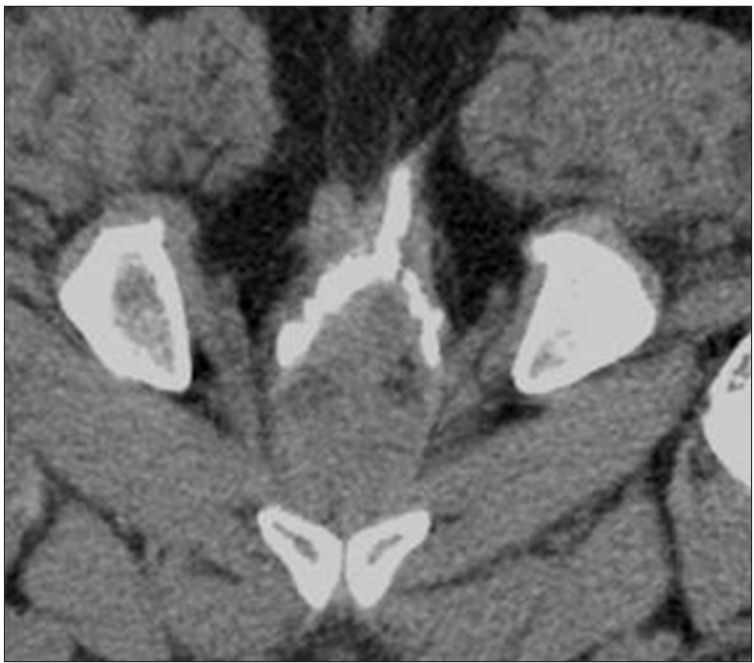

Figure 10. Complex trans-sphincteric fistula. A tract is seen in the midline traversing through the external sphincter to enter the inter-sphincteric plane and forming a horseshoe tract

levator plate (extra-sphincteric). It is either a simple or complex tract. Fistulas with multiple tracts, horseshoeing, and supralevator extensions are classified as complex tracts besides trans-sphincteric, supra-sphincteric, extrasphincteric, and recto-vaginal fistulas. Involvement of

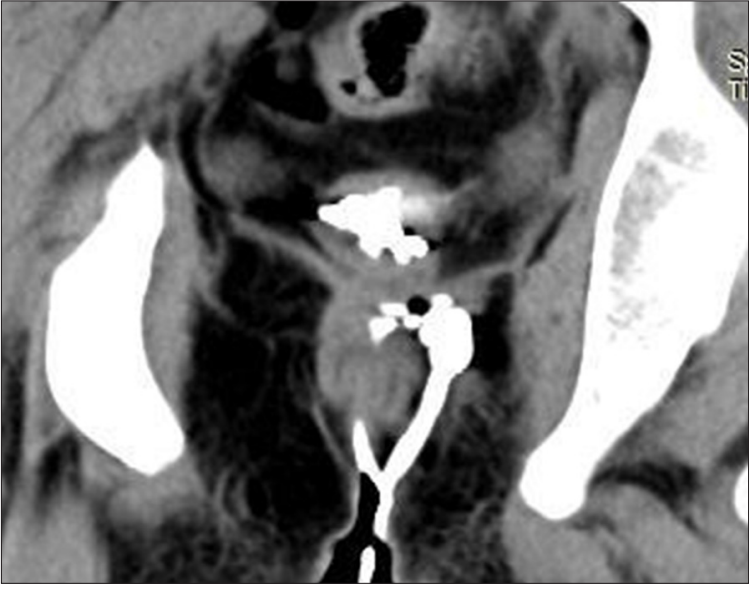

Figure 11. Supra-sphincteric tract. The tract is seen to extend superiorly in the extra-sphincteric space on the left, turns medially to traverse the pubo-rectalis and descends down the inter-sphincteric space to open in the midline posteriorly. A collection is seen in the infra-levator extrasphincteric space. This collection corresponded to the abscess. This is a complex fistula.

the ischioanal or ischiorectal fossa by a fistulous tract or abscess indicates a complex disease related to trans-sphincteric or supra-sphincteric disease (Figure 12A, 12B).

Secondary tracts are ramifications of the main primary tract and may extend in any direction to involve adjacent structures/spaces above or below the levator ani muscle. They may also communicate with the peri-anal skin, bowel, vagina, and rarely extend through long distances in the peri-anal or pelvic soft tissues (Figure 13).

Abscesses that widen the tract and pus collections can form in any location (Figure 14A-C) Sometimes, MDCTF may indicate an alternative diagnosis that can superficially mimic a fistula-in-ano.

\section{Conclusions}

MDCT fistulography is a promising technique that is capable of showing all components of fistula-in-ano and all types of peri-anal fistulas, with presentation of convincing images. More experience with this modality is required to ascertain its diagnostic accuracy as an alternative to MRI 


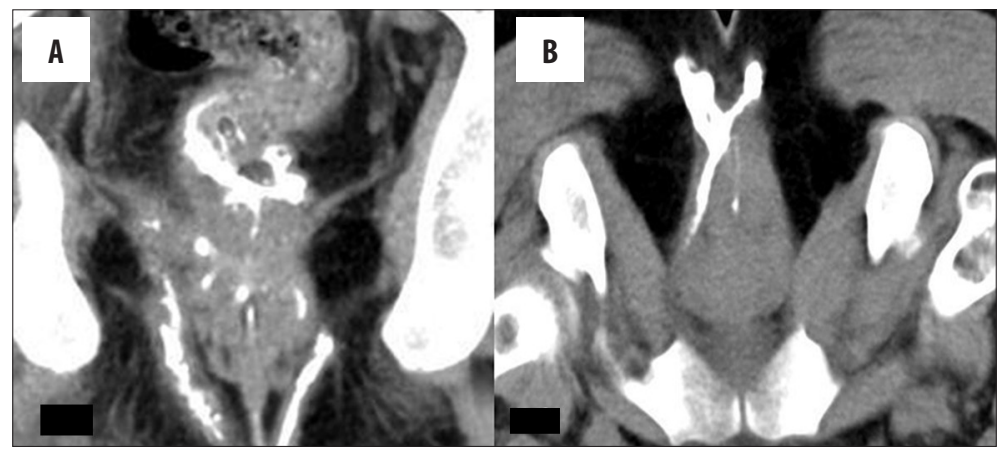

Figure 12. (A) Complex fistula. MPR image shows the infra-levator part of a thick extra-sphincteric component of the primary tract seen to reach up to the right levator muscle that is bulky and shows surrounding fat stranding. No supra-sphincteric component is recognized. Multiple branches are seen in the sphincter complex, with a tract seen in the left ischioanal space (this was a trans-sphincteric tract not evident on this image). The lower rectal wall is appearing thickened with evidence of perirectal fat stranding is this coronal view. (B) Axial thick MPR image showing a complex trans-sphincteric fistula in a female patient. A double trans-sphincteric tract is evident with multiple branches; an external tract forms a horseshoe tract in the posterior anal fat; an anterolateral tract in the inter-sphincteric plane terminating in the right pubo-rectalis muscle; a thin midline tract piercing the internal sphincter with an internal opening is seen as a dot of contrast at 6 o'clock position.

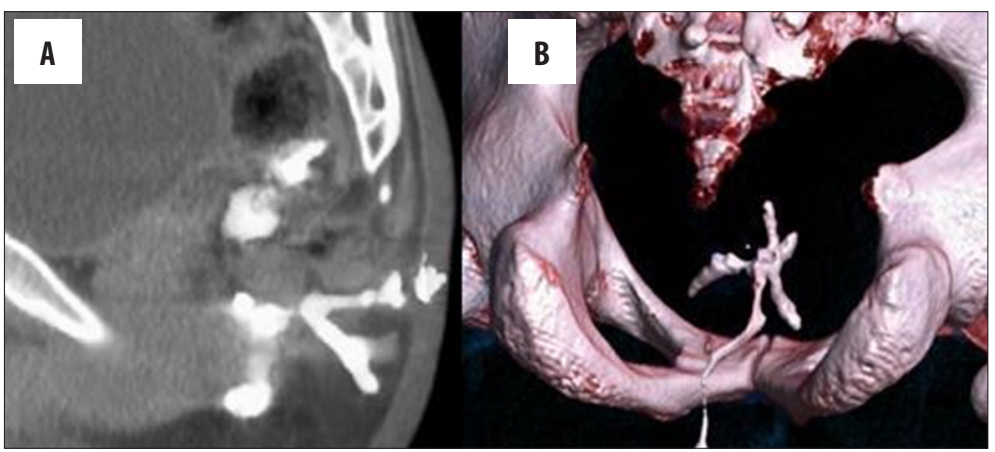

Figure 13. Secondary tract. (A) Sagittal thick MIP image showing multiple branching tracts. (B) VRT image showing all branches of the tract.

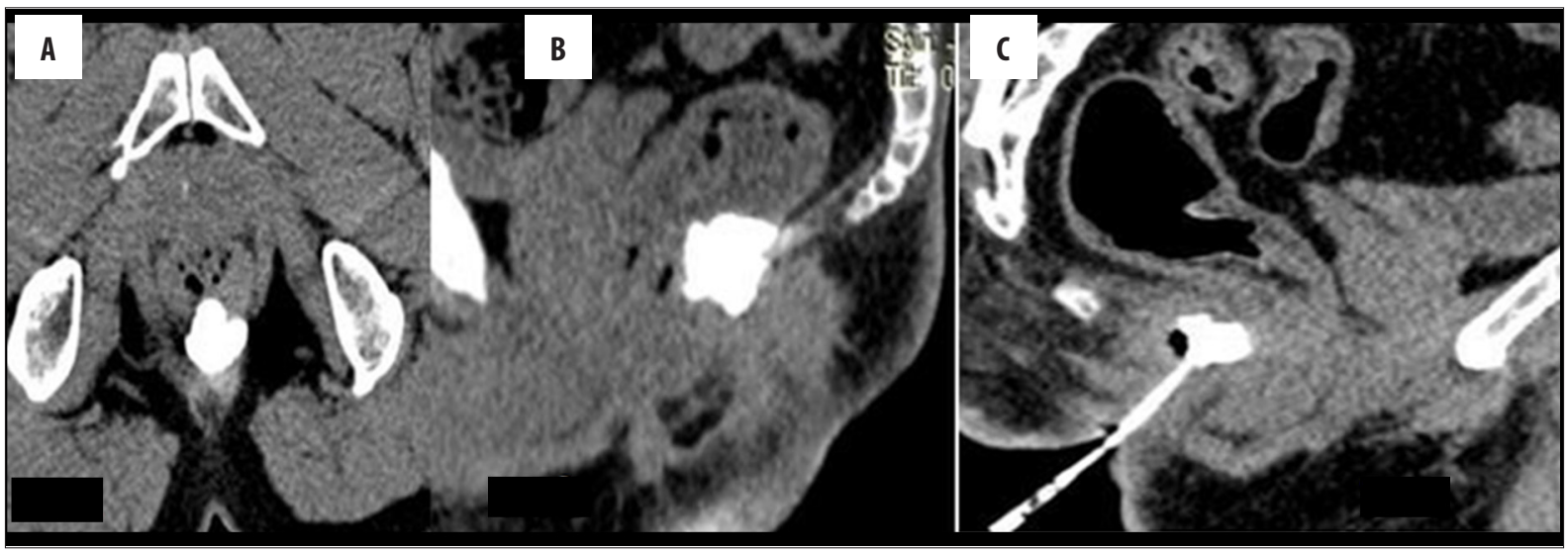

Figure 14. Abscess: (A) Axial and (B) sagittal view of an abscess seen as a contrast collection both above and below the levator, suggestive of an infra-levator abscess with a supra-levator extension and also extension into the rectal wall. (C) An abscess is seen in the deep post-anal space communicating directly with the inter-sphincteric tract.

\section{References:}

1. Sainio P: Fistula-in-anoin defined population. Incidence and epidemiological aspects. Ann Chir Gynaecol, 1984; 73: 219-24

2. Practice parameters for treatment of fistula-in-ano: Supporting documentation. The Standards Practice Task Force. The American Society of Colon and Rectal Surgeons. Dis Colon Rectum, 1996; 39: 1363-72

3. Law PJ, Bartram CI: Anal endosonography: Technique and normal anatomy. Gastrointest Radiol, 1989; 14: 349-53
4. Seow-Choen F, Phillips RKS: Insights gained from the management of problematical anal fistulas at St. Mark's Hospital, 1984-88. Br J Surg, 1991; 78: 539-41

5. Lilius HG: Fistula-in-ano, an investigation of human foetal anal ducts and intramuscular glands and a clinical study of 150 patients. Acta Chir Scand Suppl, 1968; 383: 7-88

6. Barker PG, Lunniss PJ, Armstrong P et al: Magnetic resonance imaging of fistula-in-ano: technique, interpretation, and accuracy. Clin Radiol, 1994; 49: 7-13 
7. Spencer JA, Ward J, Beckingham IJ et al: Dynamic contrastenhanced MR imaging of perianal fistulas. Am J Roentgenol, 1996; 167: 735-41

8. Kuijpers HC, Schulpen T: Fistulography for fistula-in-ano: Is it useful? Dis Colon Rectum, 1985; 28: 103-4

9. Halligan S, Jaap SL Imaging of fistula-in-ano. Radiology, 2006; 239 18-33

10. Weiming P, Yanping L: Diagnosis of 32 patients with anal fistula by multilayer spiral CT. Hebei Medicine, 2010; 7: 11-13

11. Hifeng M, Song W, Xifu W: The three-dimensional reconstruction of multislice spiral CT fistulography in preoperative assessment of fistula in anal fistula. Journal of Clinical Radiology, 2007; 6: 1027-31

12. Song W, Hai-feng MA, Xi-fu W, Bing XU. Fistula-in-ano: Assessment of fistulography of multislice spiral CT. Chinese Journal of Radiology, 2007; 5: 34-37

13. Goodsall DH, Miles WE: Diseases of the anus and rectum. London, England: Longmans, Green, 1900

14. Milligan ET, Morgan CN: Surgical anatomy of the anal canal with special reference to anorectal fistulas. Lancet, 1934; 2: 1213-17

15. Park AG: Pathogenesis and treatment of fistula-in-ano. BR Med J, $1961 ; 5224: 463-469$

16. Parks AG, Gordon PH, Hardcastle JD: A classification of fistula-inano. Br J Surg, 1976; 63(1): 1-12

17. Morris J, Spencer JA, Ambrose NS: MR imaging classification of perianal fistulas and its implications for patient management. Radiographics, 2000; 20: 623-35

18. Spencer JA, Chapple K, Wilson D et al: Outcome after surgery for perianal fistula: predictive value of MR imaging. Am J Roentgenol, 1998; 171(2): 403-6
19. Maconi G, Ardizzone S, Greco S et al: Transperineal ultrasound in the detection of perianal and rectovaginal fistulas in Crohn's disease; Am J Gastroenterol, 2007; 102: 2214-19

20. Weisman RI, Orsay CP, Pearl RK, Abcarian H: The role of fistulography in fistula-in-ano. Dis Colon Rectum, 1991; 34: 181-84

21. Orsoni P, Barthet M, Portier F et al: Prospective comparison of endosonography, magnetic resonance imaging and surgical findings in anorectal fistula and abscess complicating Crohn's disease. Br J Surg, 1999; 86: 360-64

22. Schwartz DA, Wierseman MJ, Dudiak KM et al: A comparison of endoscopic ultrasound, Magnetic resonance imaging and exam under anaesthesia for evaluation of Crohn's perianal fistula. Gastroenterology, 2001; 121: 1064-72

23. Kruskal JB, Kane RA, Morrin MM: Peroxide-enhanced anal endosonography: Technique, image interpretation, and clinical applications. Radiographics, 2001; 21 Spec No: S173-89

24. Singh K, Singh N, Thukral CL et al: Magnetic resonance imaging (MRI) evaluation of perianal fistulas with surgical correlation. J Clin Diagn Res, 2014; 8(6): RC01-4

25. DeSouza NM, Gilderdale DJ, Coutts GA et al: MRI of fistula-inano: A comparison of endoanal coil with external phased array coil techniques. J Comput Assist Tomogr, 1998; 22: 357-63

26. Halligan S, Bartram CI: MR imaging of fistula-in-ano: Are endoanal coils the goldstandard? Am J Roentgenol, 1998; 171: 407-12

27. Beckingham IJ, Spencer JA, Ward J et al: Prospective evaluation of dynamic contrast enhanced magnetic resonance imaging in the evaluation of fistula in ano. Br J Surg, 1996; 83(10): 1396-98

28. Buchanan GN, Halligan S, Taylor S et al: MRI of Fistula-in-ano: Inter- and intraobserver agreement and effects. Roentgenol, 2004; 183(1): 135-40 